\title{
EMERGO: A methodology and toolkit for efficient development of serious games in higher education
}

Citation for published version (APA):

Nadolski, R., Hummel, H., Van den Brink, H., Hoefakker, R., Slootmaker, A., Kurvers, H., \& Storm, J. (2008). EMERGO: A methodology and toolkit for efficient development of serious games in higher education.

Simulations \& Gaming, 39(3), 338-352. https://doi.org/10.1177/1046878108319278

DOI:

$10.1177 / 1046878108319278$

Document status and date:

Published: 01/09/2008

Document Version:

Peer reviewed version

Please check the document version of this publication:

- A submitted manuscript is the version of the article upon submission and before peer-review. There can be important differences between the submitted version and the official published version of record. People interested in the research are advised to contact the author for the final version of the publication, or visit the DOI to the publisher's website.

- The final author version and the galley proof are versions of the publication after peer review.

- The final published version features the final layout of the paper including the volume, issue and page numbers.

Link to publication

\section{General rights}

Copyright and moral rights for the publications made accessible in the public portal are retained by the authors and/or other copyright owners and it is a condition of accessing publications that users recognise and abide by the legal requirements associated with these rights.

- Users may download and print one copy of any publication from the public portal for the purpose of private study or research.

- You may not further distribute the material or use it for any profit-making activity or commercial gain

- You may freely distribute the URL identifying the publication in the public portal.

If the publication is distributed under the terms of Article 25fa of the Dutch Copyright Act, indicated by the "Taverne" license above, please follow below link for the End User Agreement:

https://www.ou.nl/taverne-agreement

Take down policy

If you believe that this document breaches copyright please contact us at:

pure-support@ou.nl

providing details and we will investigate your claim.

Downloaded from https://research.ou.nl/ on date: 26 Apr. 2023 


\title{
EMERGO: methodology and toolkit for efficient development of serious games in higher education
}

Rob Nadolski*, Hans Hummel, Henk van den Brink, Ruud Hoefakker, Aad Slootmaker, Hub Kurvers, Jeroen Storm Open University of the Netherlands

\begin{abstract}
Societal changes demand education to apply new pedagogical approaches. Many educational stakeholders feel that serious games could play a key role in fulfilling this demand, and smack their chops when looking at the booming industry for leisure games. However, current toolkits for developing leisure games show severe shortcomings for the development of efficient and effective serious games. Furthermore, developing serious games asks for a specific approach which differs from the approach used in developing leisure games. EMERGO provides a methodology and generic toolkit for developing and delivering serious games aimed at the acquisition of complex cognitive skills in higher education. This article describes the EMERGO methodology and toolkit and preliminary evaluation results with case developers using EMERGO methodology and toolkit as well as learners using EMERGO cases.
\end{abstract}

Keywords: higher education; methodology; multimedia practicals; serious games; toolkit.

There is continuous demand for education to update their pedagogical approaches and apply them in cost-efficient ways. Rapid changes in today's labour market require suitable approaches to lifelong education. New generations of learners are needing new pedagogical approaches to stay motivated (Prensky, 2001). Motivation can be considered to be the key aspect of effective learning (Ryan \& Deci, 2000; Garris et al., 2002). For many educational stakeholders, serious games seem the answer to such demands (Nadolski et al., 2006b). However, in order to fulfil these demands we first need to overcome the severe costs in developing serious games. Serious games development demands a specific methodology for its design, development and delivery. Such a methodology does not only support the design and development of serious games, but also provides guidelines on how such games could be effectively distributed and used. Although many methodologies for leisure games development already exist, their suitability for serious games development can be questioned (Aldrich, 2005). The use of these existing methodologies and their toolkits might even be detrimental for developing serious games in higher education.

EMERGO offers a more specific methodology and generic toolkit for efficient development and delivery of multimedia cases for acquiring complex cognitive skills in higher education. EMERGO cases are delivered via the Internet and will foster active and cooperative learning in a realistic, practice-based setting. This can be achieved by using gaming elements, simulation elements and pedagogical elements, and by including both system-based-, teacher- and peer support (Aldrich, 2005). This approach is inline with the multimodal and multimedial reality of the next generation of learners (Prensky, 2001). Through EMERGO cases, learners are engaged in both a rich and challenging learning environment where they encounter realistic problem situations, and constantly are being confronted with the consequences of their acts. This way, learning experiences become personalized and learners stay motivated.

The EMERGO methodology and toolkit as such do not guarantee the development of effective, attractive and efficient learning experiences. This would presume the presence of both expertise in designing and developing serious games and of high quality content. A key challenge for serious games designers is to find an optimal combination of delightful play and achieving specified learning outcomes.

Serious games could be used to study their learning effectiveness within higher education settings. In this way, two current limitations of the uptake of games in higher education can be addressed, namely a lack 
of empirical data on their current effects and a lack of understanding of how games could be used most effectively (de Freitas, 2006).

Although EMERGO still is work-in-progress, its methodology and toolkit have been build upon extensive experience at the Open University of the Netherlands with the development of single user, stand alone serious games (e.g., Gerrichhauzen et al., 1998; Hommes et al., 2000; Huysse et al., 1998; Wöretshofer et al., 2000), and upon accompanying research into such games (Hummel et al., 2006; Nadolski et al., 2006a). EMERGO games will be distributed by the Internet, will be more flexible with respect to pedagogical approaches as well as to learners, and will be more user-friendly for all stakeholders. Currently, first evaluation results on using the EMERGO methodology and toolkit and its resulting cases confirm these claims.

\section{EMERGO methodology}

The EMERGO methodology is tuned to serious games for acquiring complex cognitive skills (referred to as cases) and takes ADDIE, a well-known phasing approach for instructional materials (Plomp, Feteris, Pieters, \& Tomic, 1992) as a starting point. It also adopts Unified Processing, an approach for software development (Kruchten, 2004). Both are transformed and extended towards the domain of serious games. ADDIE is an abbreviation of Analysis, Design, Development, Implementation and Evaluation (see Figure 1). From now on, these phases will be further described in the context of EMERGO.

Although all phases can be conducted in this order, it is recommended to use iterations. In other words, use a Unified Process approach with cycles instead of the classical waterfall approach. Design assumptions and expectations can be tested during development, and gradually a uniform picture can arise that is supported by the whole project team.

Being based upon ADDIE and Unified Process, the EMERGO methodology prevents overspending and minimizes risks of failures. Case parts will be developed and tested in cycles, which results in more intense and frequent - but not necessarily more time consuming - communication between various stakeholders.

An important precondition for enabling shorter cycles is the ability to carry them out quick and easy. The EMERGO toolkit caters for this need.

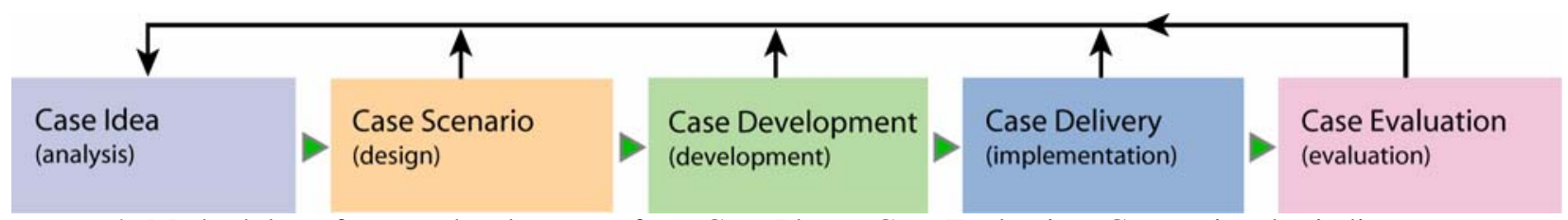

Figure 1. Methodology for case development: from Case Idea to Case Evaluation. Green triangles indicate an advised order but phases can be conducted iteratively (black arrows). See EMERGO Website for this and other figures (http://www.emergo.cc).

The five EMERGO phases and the toolkit are now described in some more detail.

Phase 1: Analysis

At the start, case developers need to consider various issues related to the intended case. By discussing them, the project team gains more insight, and more awareness for the case will arise: why is it needed, for whom is it meant, what will be in it, how will it be structured? A realistic picture of possibilities and impossibilities emerges before actually starting case design and development. By answering - an appropriate subset of - the questions in Table 1, the team provides a global description of the intended case.

After providing - provisional - answers to these questions, the project team finishes the analysis phase by providing this global description as input document for the design phase. 
Table 1. Questions for Analysis.

\begin{tabular}{|c|c|}
\hline Subject & Questions \\
\hline \multirow[t]{4}{*}{ Case embedding } & For which courses, curricula and institutions will it be used? \\
\hline & Is it a stand-alone item or used with other instructional materials? \\
\hline & What study load and time interval is expected? \\
\hline & How many credit points earn students by successfully completing it? \\
\hline \multirow[t]{23}{*}{ Case content } & What is the main complex cognitive skill? \\
\hline & Do other complex cognitive (sub) skills need to be acquired? \\
\hline & What subject matter domain(s) are involved? \\
\hline & What prior knowledge and skills are expected for enrolled students? \\
\hline & What is central to the case (for example: patient, equipment, process)? \\
\hline & What are physical locations in the case? (try to map them to virtual spaces) \\
\hline & What case characters are relevant? \\
\hline & Do students need to proceed via a stepwise procedure? \\
\hline & $\begin{array}{l}\text { What kind of activities do students need to perform for acquiring the main complex cognitive } \\
\text { skill? }\end{array}$ \\
\hline & Is there a strict order for the compulsory tasks? \\
\hline & Are there compulsory tasks, non-compulsory tasks and what determines this? \\
\hline & Is redundant information provided, or is everything strictly needed? \\
\hline & How realistic and authentic is the case? \\
\hline & If students can redo a case: will this be the same case or a variant? \\
\hline & Can students undo former decisions? \\
\hline & Are different learning routes and tasks for different students offered? \\
\hline & What kind of cooperation is needed by students? \\
\hline & Do students have different case characters? \\
\hline & Do students have active roles? \\
\hline & Do teachers have active roles? \\
\hline & What aspects induce and sustain interest and motivation? \\
\hline & What unforeseen circumstances are incorporated? \\
\hline & $\begin{array}{l}\text { Is competition incorporated? How do students get rewarded for excellent performance or } \\
\text { behaviour? }\end{array}$ \\
\hline \multirow[t]{5}{*}{ Students' progress } & How do students discover not yet having acquired the main complex cognitive skill? \\
\hline & How can students monitor their progress? \\
\hline & How is it checked if students have acquired the main complex cognitive skill? \\
\hline & Is summative assessment included and are its results used in formative assessment? \\
\hline & Which students' progress figures are to be used by teachers during run time? \\
\hline \multirow[t]{3}{*}{ Contact with peers } & Should contact between students be encouraged? \\
\hline & Should students see if peers are on line, when they have been on line? \\
\hline & Can students compare their progress with peers? \\
\hline \multirow[t]{3}{*}{ Using media } & Will existing material be used, is new material needed? \\
\hline & What media genres are used (e.g., interviews, docudrama, movie, animations)? \\
\hline & What media assets are needed and what are their costs? \\
\hline \multirow{3}{*}{ Case delivery } & Is the number of students within one run restricted? \\
\hline & When can students enrol for a run? \\
\hline & Is it possible to change the case after starting a run? \\
\hline \multirow[t]{2}{*}{ (embedded) Support } & How will technical support be provided? \\
\hline & How will support be provided for acquiring the main complex cognitive skill? \\
\hline \multirow[t]{3}{*}{ Costs } & How many students will enrol each year? \\
\hline & What are the development costs per student? \\
\hline & What is the expected teacher/student ratio during exploitation? \\
\hline \multirow[t]{2}{*}{ IPR } & Is it allowed for others to use the case? \\
\hline & $\begin{array}{l}\text { Are materials from other parties incorporated and what are their Intellectual Property } \\
\text { Rights(IPR) arrangements? }\end{array}$ \\
\hline
\end{tabular}


Phase 2: Design

The design phase needs to result in a detailed scenario document via the intermediate steps framework scenario and ingredients scenario. Each step provides more detail and completeness.

\section{Framework scenario}

This step describes the global activities students carry out during the case. A standard format for noting activities is proposed "Where the student will... $<$ description of the activity $>$ ". This enables to identify a first series of activities without getting overwhelmed by details (first advantage). In this series, one can already distinguish between compulsory and non-compulsory activities, activities that need to be performed in a certain order or not, activities unexpectedly popping up or being in the students' 'to dolist'. The approach quickly provides a blue print for issues to be further worked upon (second advantage). The framework scenario resembles a construction drawing for a building. The team does not need to spend too much time on detailing out certain elements at the beginning (third advantage). It enables giving similar attention to all elements at several stages during design and development. The framework scenario can flexibly be adjusted during following steps.

\section{Ingredients scenario}

The framework scenario is the second, more detailed step of the design phase. For each activity it is identified how students are to perform: what does the student do, with whom, with what tools and resources, and with which support (teacher, fellow student, or embedded)? Does task performance result in a product, and if so, how will this be evaluated? Is a sufficient result needed before students can carry on? What are foreseen interactions with other participants and the program during and after carrying out an activity? The (possible) interactions for each activity are exhaustively described, but not yet in terms of required tools and resources.

\section{Detailed scenario}

This final step of the design phase describes each activity exhaustively in terms of its required tools and resources to enable the actual performance. If students can interview a person, all interview questions need to be identified; if students need to read resources, all resources need to be identified. At this point, it also becomes clear if case materials are already available or still need to be developed. Furthermore, all tools are identified. The EMERGO toolkit contains several components for developing such tools and can be extended. So, mostly no additional tool development is needed. Using Flowcharting and Scheduling software for this step is heavily recommended.

\section{Phase 3: Development}

During this phase, the EMERGO-toolkit is used for data entry with the detailed scenario providing guidance. Ideally, data entry does not need any specific case expertise, but this seldom occurs. Intensive and cyclic testing during data entry is needed and often identifies issues that can only be quickly resolved by case experts. Therefore, the design and development teams will need considerable overlap. Furthermore, data entry and testing are interdependent and might require specific expertise. Thus, it is important to agree on a specific working procedure. A content management system is indispensable for efficient version management of all digital case assets.

During development, three different roles are distinguished:

1. Case owner (responsible for setting access rights for components)

2. Component author (is responsible for data entry of a specific part of the case)

3. Case tester (needs to be able to switch between the various case characters)

A number of case characters will need to be defined, depending on the authentic learning environment the case represents. Evidently, the case character 'student' will always be available and the case character 'teacher' is very unlikely to be missing. However, students might play other characters (for example: president, minute's secretary, debater). If so, the case tester should be able to test each of them. 
Figure 2 shows a screen from the student environment. The student can manoeuvre between locations. Students can activate the Empack that incorporates tools students can use during task performance. Students can always take notes that are automatically classified in a so-called Logbook. Students can choose tasks in the 'to do list', but within constraints as defined by the case developers.

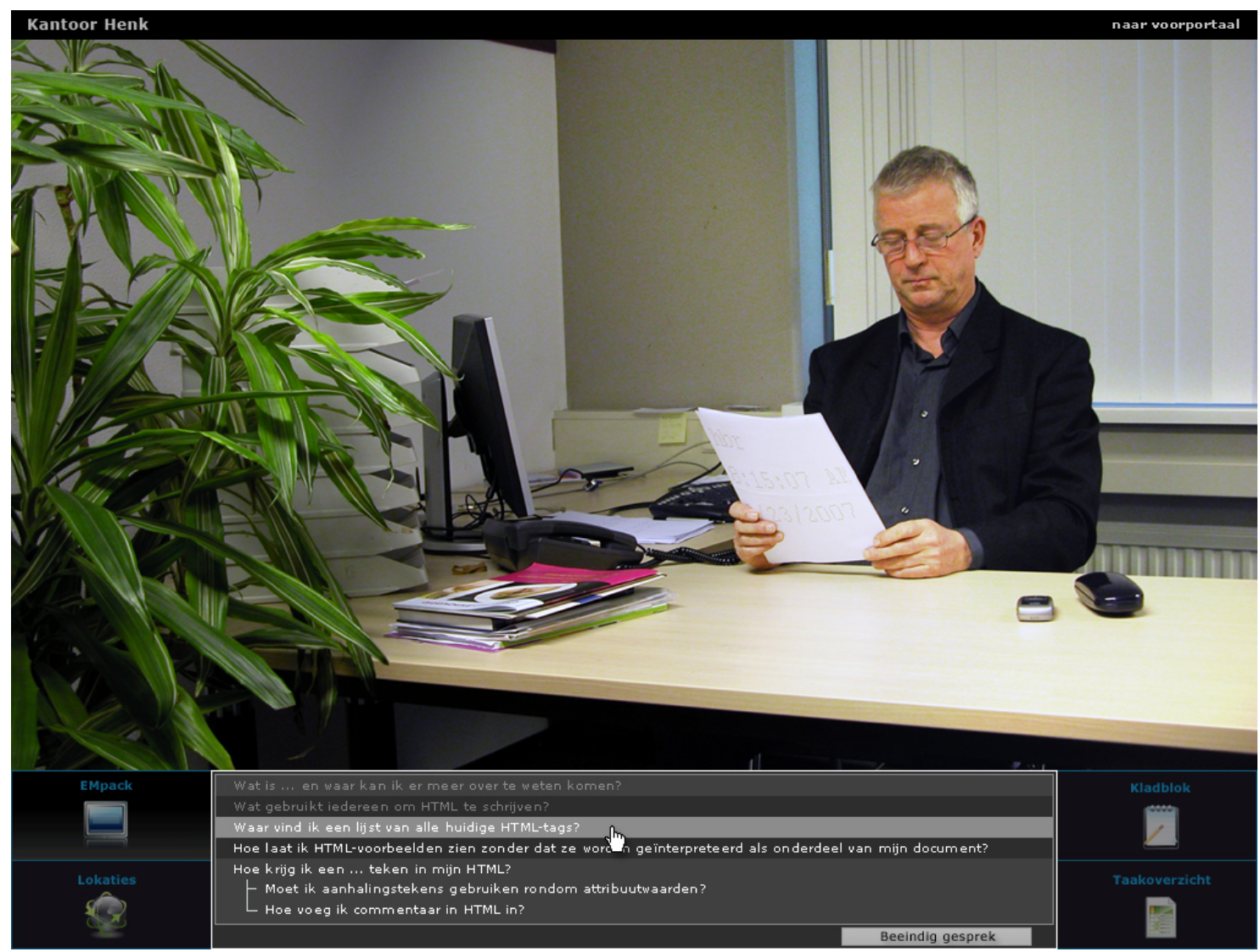

Figure 2. Screen dump of the student environment. Components are graphically represented. Here, a student can ask questions to a person in his office.

\section{Global description of the EMERGO toolkit}

In this section we will provide an impression of how students interact with the student environment as well as a first idea of the EMERGO toolkit possibilities.

Successively, EMERGO toolkit components for the data entry environment are described.

In the study environment, students can conduct conversations, visit locations, use equipment or tools, can participate in discussions et cetera.

For learning to take place, students need to record their impressions and attach meaning to them.

Therefore, students can take notes in various ways:

1. Take notes at locations. This can be during a conversation, when reading a document, using the Notebook in their environment.

2. Arranging and processing notes taken. The Logbook automatically classifies all notes from the Notebook. Students can summarize, can make overviews and draft reports using their Logbook.

3. Final reports. Drawing up a report can be a product of a task made via using Clipboard and Logbook. Reports can be uploaded via e-messages.

4. Constitute e-messages. A report can be attached to an e-message.

As appears from Figure 3 and Table 2, components for data entry can be used for both initialisation and development. 


\section{Case Development}

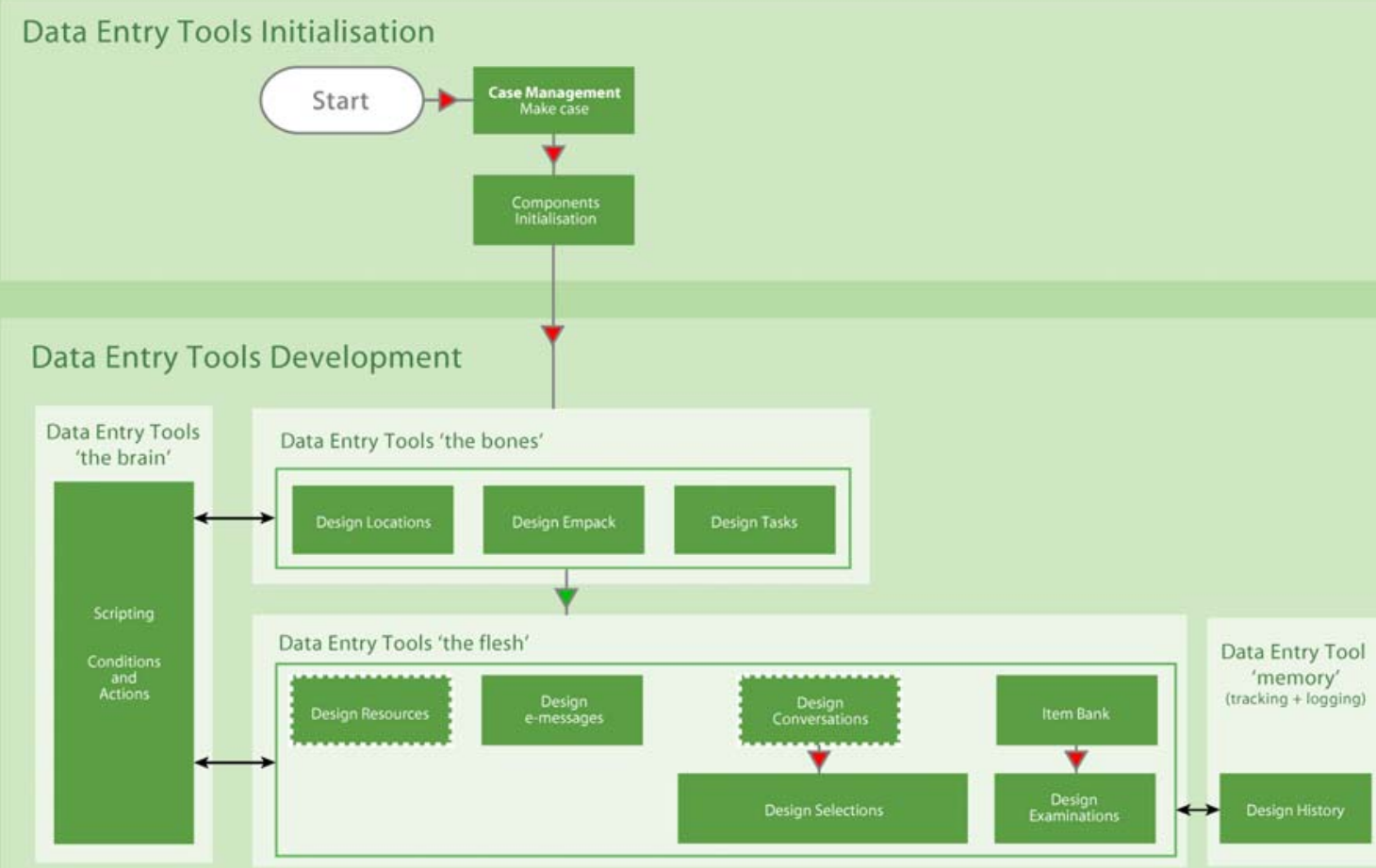

Figure 3. Data entry components for case development. Red arrows indicate a compulsory order, the green arrow indicates an advised order. If components are in the same box, it is impossible to indicate an advised order. Bidirectional arrows indicate relationships between components. The component Scripting is at the centre of all data entry. It defines the case flow using conditions and actions.

Table 2 summarizes various data entry components and their functionality. Almost every component can be used (instantiated) several times in the student environment. For example: "design resources" enables making a 'video archive', a 'file cabinet', a 'resource collection'.

Table 2. Data entry components and their function. Grey components relate to initialisation, non-coloured components are used for development.

\begin{tabular}{|l|l|}
\hline Component & Function \\
\hline Case Management: Make case & Defines new cases. Existing cases can be used for modding. \\
\hline Components Initialisation & Defines all components and their access rights for data entry. \\
\hline Design Locations & Defines locations between and possibly conditions and actions. \\
\hline Design Empack & Defines tools on the Empack and possibly conditions and actions. \\
\hline Design Tasks & Defines tasks in the 'to do list' and possibly conditions and actions. \\
\hline Scripting & $\begin{array}{l}\text { Defines the case flow by conditions and actions that can specified for the } \\
\text { complete case, one or more other components, or specific data entry for one } \\
\text { or more components. Conditions and actions often relate to student actions } \\
\text { but also to other actors actions. }\end{array}$ \\
\hline Design Resources & Defines resources and their hierarchies. \\
\hline Design e-messages & Defines various types of e-messages. \\
\hline Design Conversations & Define conversations between students and virtual characters. \\
\hline Design Selections & Defines selection options for students when performing a task. \\
\hline Item Bank & Defines multiple choice items for examinations. \\
\hline Design Examinations & Defines examinations. \\
\hline Design History & Defines to be logged student choices and retrievable by students. \\
\hline
\end{tabular}




\section{Testing data entry}

Testing involves switching between case characters. There are three ways of testing:

- $\quad$ start and use results from the previous session (default)

- $\quad$ start and use results from another - not the previous- session (using demo-runs)

- $\quad$ start and do not use results from another session

It is possible to test components in isolation or in connection.

\section{Phase 4: Implementation}

During implementation, the case is accessed by certain students and teachers. Figure 4 shows data entry components for case delivery, whereas Table 3 summarizes these components and their functionality.

Case delivery assumes:

- $\quad$ a student can choose the case in his study environment (student portal)

- a teacher can choose the case in his work environment (teacher portal)

- $\quad$ data entry for the case has been checked and is OK

- $\quad$ case run management has been used to prepare the run for the case to be launched

If so, the case can be "published". Certain students and teachers can choose the case via the EMERGOWebsite using their authorization-data.

Table 3. Data entry components and their function.

\begin{tabular}{|l|l|}
\hline Component & Function \\
\hline Design Portfolio & Defines which student-products are added to their Portfolio. \\
\hline Design Student Portal & $\begin{array}{l}\text { Defines which cases can be chosen, what case progress data can be } \\
\text { monitored, progress comparisons, et cetera. }\end{array}$ \\
\hline Design Teacher Portal & $\begin{array}{l}\text { Defines which cases can be chosen, what case progress data can be } \\
\text { monitored for which students, et cetera. }\end{array}$ \\
\hline Case Management: Check case & Checks whether data entry is syntactically correct. \\
\hline Case Run Management & $\begin{array}{l}\text { Defines case runs. Each run has a start time, enrolled students, enrolled } \\
\text { teachers and could have an end time. }\end{array}$ \\
\hline
\end{tabular}

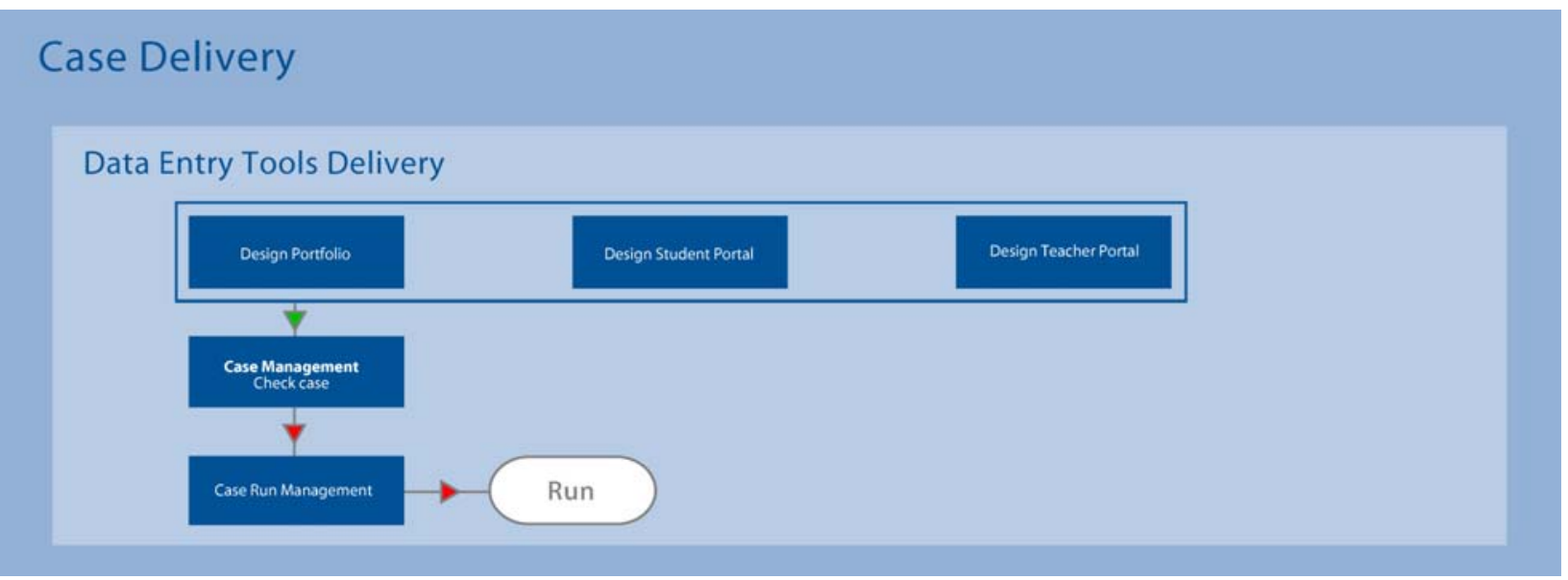

Figure 4. Data entry components for case delivery. Red arrows indicate a compulsory order, the green arrow indicates an advised order. If components are in the same box, it is impossible to indicate an advised order. 
Phase 5: Evaluation

Evaluation will assess whether the case fulfils the initial demands defined during analysis: is the actual use in line with its expected use? A clear evaluation focus before launching the case should be made explicit in an evaluation plan. In principle, in the evaluation phase, answers to questions in the analysis phase can now be checked (see Table 4).

Table 4. Questions for evaluation.

\begin{tabular}{|l|l|}
\hline Subject & Questions \\
\hline Case embedding & What courses, curricula and institutions did use the case? \\
\hline & Is the case exploited as stand-alone item or with other instructional materials? \\
\hline Case content & What study load and time interval is measured? \\
\hline & Did students acquire the main complex cognitive skill? \\
\hline & Did students have the assumed prior knowledge and skills? \\
\hline & Did students perform tasks as expected? \\
\hline & Did students consult resources as expected? \\
\hline & Did students cooperate as expected? \\
\hline & Did students use peer support? \\
\hline & Did teachers perform as expected? \\
\hline & Did students enjoy the case and where they immersed? \\
\hline Students' progress & What unforeseen circumstances did students encounter during the case? \\
\hline & What rewards did students receive during case performance? \\
\hline & How did students discover if they had acquired the main complex cognitive skill? \\
\hline Contact with peers & How and when did students monitor their progress? \\
\hline & What where teachers' actions on students' progress? \\
\hline (embedded) Support & Did students get in touch with peers? \\
\hline & Did students compare their progress with peers? \\
\hline Costs & $\begin{array}{l}\text { How often did students ask for technical support and was this sufficient? } \\
\text { was this sufficient? }\end{array}$ \\
\hline & How many students enrolled the case? \\
\hline & What teacher/student ratio was measured during exploitation? \\
\hline
\end{tabular}

\section{Evaluation results}

This section describes preliminary evaluation results for (a) case developers using the EMERGO methodology and toolkit for five cases in the field of environmental policy and (b) students using three of aforementioned cases during their study.

EMERGO methodology and toolkit

We wanted to investigate whether case developers were capable of using the methodology and toolkit independently, and what improvements would be needed. Case developers $(n=5)$ used the EMERGO methodology and toolkit for five cases. The estimated study time for those cases is 60 hours whereas it took about 1500 hours to develop them (e.g., production ratio of 1:25). The five cases differed in complexity, but no detailed figures were collected to compare the production ratio for each of them.

\section{Process and instruments}

This evaluation consisted of an electronic questionnaire and a face-to-face focussed interview. The questionnaire included five questions (each with about a dozen items) that made an inventory of the extent in as how far the methodology and components from the toolkit were used as well as their appreciation. Most items had predefined alternatives but also left room for open answers. Four respondents returned the questionnaire. The results from the questionnaire were used to design the focussed interview which was held within a week after collecting the questionnaires. The interview aimed to identify improvements for both methodology and toolkit and was conducted with four case developers and lead by the evaluator. 


\section{Results}

Respondents unanimously indicate that the EMERGO methodology clearly supports them during the phases in a flexible way, but needs more concrete guidelines and examples. This is especially needed for a smooth transition from detailed scenario towards data entry. Case developers indicate that they expect a multidisciplinary team will be needed for more complex case development and that their experience after using the methodology was improved.

Respondents extensively used the EMERGO-toolkit, but did not all use the same components. Table 5 summarizes respondents' scores on suitability and simplicity for independently using toolkit components as they were needed for producing the five cases. Their scores showed that only the component Scripting induced problems for independent use. The components Scripting and Design Conversations were most difficult to use. Most components from the toolkit already were very user friendly, but the components Scripting and Design Conversations will need further improvement, especially for more complex cases as such were produced during this evaluation. It is suggested to incorporate a context dependent help function when working with the toolkit.

Table 5. Suitability and simplicity for independently using EMERGO-toolkit components $(n=4)$

\begin{tabular}{|c|c|c|c|c|c|c|c|}
\hline Component & $\begin{array}{l}\text { Used? } \\
\text { yes }\end{array}$ & $\begin{array}{l}\text { Independent? } \\
\text { yes }\end{array}$ & no & $\begin{array}{r}\text { Simple? } \\
1 \\
\text { Completely } \\
\text { disagree }\end{array}$ & 2 & 3 & $\begin{array}{l}4 \\
\text { Completely agree }\end{array}$ \\
\hline Design Locations & 4 & 4 & & & & 2 & 2 \\
\hline Design Empack & 2 & 2 & & & & & 2 \\
\hline Design Tasks & 3 & 3 & & & & 2 & 1 \\
\hline Scripting & 3 & 2 & 1 & 2 & 1 & & \\
\hline Design Resources & 4 & 4 & & & & 2 & 2 \\
\hline Design e-messages & 4 & 4 & & & & 3 & 1 \\
\hline Design Conversations & 4 & 4 & & & 2 & 2 & \\
\hline Case Run Management & 2 & 2 & & & & 1 & 1 \\
\hline
\end{tabular}

\section{EMERGO cases}

This evaluation wanted to investigate whether (a) the technique from the Web interface was adequate, (b) the user-interface was user friendly and (c) how the cases were appreciated by the students. Students from the Open University of the Netherlands $(\mathrm{n}=8)$ used three EMERGO cases within their course Environmental Policy when studying for regular credit points (i.c., ECTS). The estimated study time was 22 hours. The three cases showed increasing complexity and less support for students.

\section{Process and instruments}

This evaluation consisted of four questionnaires that all included questions with predefined alternatives and possibility for open answers. The evaluation consisted of three parts dealing with (1) technical aspects, (2) user-interface aspects, and (3) didactical-content aspects. The first questionnaire only contained questions for first two categories whereas the other questionnaires contained similar questions for all aspects in order to gather case-specific info for the third category. In total, thirty-five questions were provided to respondents. One respondent returned the first two questionnaires only as the cases did not function on respondents' Mac PC. Four respondents returned all questionnaires. Non-response was mainly due to private matters and practical reasons as the evaluation period was partly during the holiday season. Questback (see https:/questback.com) was used for the workflow during the evaluation. Students had about three weeks to finish the cases. A reminder was send one week before the deadline.

\section{Results}

The Web interface appeared error-prone and met most requirements. However, still a performance improvement is needed for a more smooth learning experience. This would also benefit the user interface that - despite of the performance problems - already met all expectations. More cross platform compatibility is also needed. Students were very satisfied with the user interface. They only encountered 
small problems, mainly resulting from choices made during the detailed scenario. For example: students also wanted to consult some task specific information during task performance and not only before task performance, as was provided for current cases. This could easily be adjusted with the existing toolkit components. Students were very satisfied with the cases. This was mentioned in relation to their structure, alignment with prior knowledge and skills, as well as their realism. As was stated by one of the students: "It is true to life". In other words, students were very motivated when interacting with the cases.

\section{Conclusion}

There are limited evaluation results so far. However, preliminary evaluation results clearly show that the EMERGO methodology and toolkit support serious game developers in delivering more efficient and effective serious games. A production ratio of 1:25 is pretty efficient as compared to our previous experience when producing computer based learning programs (ranging from 1:100 towards 1:600) (see Alessi \& Trollip, 2001). The five cases differed in complexity and showed that EMERGO's methodology and toolkit enable to produce a broad range of cases. However, as all cases used in this study are quite complex, their production needed quite a lot of different expertise. Students studying the cases were very satisfied and strongly motivated when interacting with them. However, as learning results were not measured during this evaluation it remains unclear whether the cases were also effective for students. Indeed, more research is needed to see whether such realistic cases are beneficial for learning.

Although the EMERGO methodology targets the development of serious games aimed for the acquisition of complex cognitive skills in higher education, this methodology can also be used for serious games aiming at more simple skills and beyond the area of higher education. Our methodology makes that serious games are easier to produce and need less specific expertise within the project team. However, still a broad range of expertise will be needed for developing serious games. Multi-disciplinary teams need to represent expertise from both information and communication technology, semiotics, narratology, cybernetics, ludology, educational psychology and instructional design. We have stressed the instructional design point of view in this article. However, this leaves untouched other expertise areas playing an equivalent important role in arriving at balanced serious games.

The broad application area of the EMERGO methodology and toolkit could further boost serious games development. More research in applying these EMERGO products is needed to further justify this claim.

\section{References}

Aldrich, C. (2005). Learning by doing: the essential guide to simulations, computer games, and pedagogy e-learning and other educational experiences. San Francisco, CA: John Wiley \& Sons.

Alessi, S. M., \& Trollip, S. R. (2001). Multimedia for learning: Methods and development. Needham, MA: Allyn \& Bacon.

De Freitas, S. (2006). Learning in Immersive worlds: A review of game-based learning. Prepared for the JISC e-Learning Programme. Last accessed, February 12, 2007 on http://www.jisc.ac.uk/eli_outcomes.html

Garris, R. , Ahlers, R., \& Driskell, J. (2002). Games, motivation and learning: A research and practice model. Simulation and Gaming, 33, 441-467.

Gerrichhauzen, J. T. G., Hoefakker, R. E., Perreijn, A. C., van den Brink, H. J., Slootmaker, A. , \& Berkhout, J. (1998). Buiten dienst [Out of order] (version 1.0) [multimedia CD-ROM]. Heerlen, The Netherlands: Open University of the Netherlands.

Hommes, M. A., Houtmans, M. A., Hummel, H. G. K., Kuntze, A. J. , Tiesnitsch, D., Rickhoff, M. L., Westera, W., Kerstjens, W. M. J., Kurvers, H. J., Slot, W. J. J., Vander Meeren, W. M. F., \& Berkhout, J. (2000). Diagnosticus [Diagnostician] (version 1.0) [multimedia CD-ROM]. Heerlen, The Netherlands: Open University of the Netherlands. 
Hummel, H. G. K., Paas, F., \& Koper, E. J. R. (2006). Effects of cueing and collaboration on the acquisition of complex legal skills. British Journal of Educational Psychology, 76(3), 613-631

Huysse, P., Nadolski, R. J., Oldenboom, E., Kerstjens, W. M. J., de Vries, F. J. J, Slootmaker, A, Jordense, M., Jambos, M., \& Berkhout, J. (1998). Paradise Parks (version 1.0) [multimedia CD-ROM]. Heerlen, The Netherlands: Open University of the Netherlands.

Kruchten, P. (2004). The Rational Unified Process: An introduction. Boston: Addison-Wesley.

Nadolski, R. J., Kirschner, P. A., \& Van Merriënboer, J. J. G.(2006a). Process support in learning tasks for acquiring complex cognitive skills in the domain of law. Learning and Instruction, 16, 266-278.

Nadolski, R. J., Van der Hijden, P., Tattersall, C., \& Slootmaker, A. (2006b). Multi-user online serious games: Policy, design and use [Multi-user online serious games: Beleid, ontwerp en gebruik]. Utrecht, The Netherlands: Stichting Digitale Universiteit. Last accessed, February 23, 2007 on http://www.surf.nl/smartsite.dws?id=12742

Plomp, T., Feteris, A., Pieters, J. M. , \& Tomic, W. (Eds.)(1992). Designing education and training [Ontwerpen van onderwijs en trainingen]. Utrecht, The Netherlands: Lemma.

Prensky, M. (2001). Digital Game-Based Learning. New York: McGraw-Hill.

Ryan, R. M., \& Deci, E. L. (2000). Self-determination theory and the facilitation of intrinsic motivation, social development, and well-being. American Psychologist, 55(1), 68-78.

Wöretshofer, J., Nadolski, R. J., Starren-Weijenberg, A. M. A. G., Quanjel-Schreurs, R. A. M., Aretz, C. C. W. M., van der Meer, N. H. W., Martijn, G., van den Brink, H. J., Slootmaker, A., \& Berkhout, J. (2000). Preparing a plea [Pleit voorbereid] (version 1.0) [multimedia CD-ROM]. Heerlen, The Netherlands: CIHO.

\section{Acknowledgement}

This article has been written in the context of the EMERGO project, supported by the SURF foundation, the higher education and research partnership organisation for Information and Communications Technology (ICT) (www.surf.nl).

\section{Biographical notes}

All authors work at the Educational Technology Expertise Centre of the Open University of the Netherlands, and are currently involved in projects for serious games development.

Rob J. Nadolski is educational technologist and his main interests focus on competence-based education and serious games, way finding facilities in Learning Networks and learning technology specification. Hans G. K. Hummel is educational technologist and his main interests focus on competence-based education and serious games, way finding facilities in Learning Networks and learning technology specification.

Henk J. van den Brink is educational technologist and his main activities concern the development of competence-based education and serious games.

Ruud E. Hoefakker is educational technologist and his main activities concern the development of competence-based education and serious games.

Aad Slootmaker is senior software developer and his main activities concern the technical design and development of interactive multimedial computer programs and serious games as well as consultancy for VLE's/PLE's.

Hub J. Kurvers is software developer and his main activities concern the development of interactive multimedial computer programs and serious games.

Jeroen Storm is graphical designer of mainly interactive multimedial computer programs and serious games.

Contact details: Rob J. Nadolski, rob.nadolski@ou.nl, Educational Technology Expertise Centre, Open University of the Netherlands, Valkenburgerweg 177, 6419 AT, Heerlen, The Netherlands. 